\title{
Magnetic effects on crystal growth rate of calcite in a constant-composition environment
}

\author{
Clifford Y. Tai ${ }^{\mathrm{a}, *}$, Meng-Chun Chang ${ }^{\mathrm{a}}$, Rong-Jong Shieh ${ }^{\mathrm{a}}$, Ted G. Chen ${ }^{\mathrm{b}}$ \\ a Department of Chemical Engineering, National Taiwan University, Taipei, Taiwan \\ b Pro-Service Water Technologies Corp., Taipei, Taiwan
}

\section{A R T I C L E I N F O}

\section{Article history:}

Received 23 November 2007

Received in revised form

25 February 2008

Accepted 20 May 2008

Communicated by J. de Yoreo

Available online 24 May 2008

PACS:

61.66.Fn

81.10.Dn

Keywords:

A1. Constant-composition

A1. Magnetic effect

A2. Crystal growth

B1. Calcium carbonate

\begin{abstract}
A B S T R A C T
The crystal growth rates of calcite in a constant-composition environment were measured in the presence of a magnetic field. The magnetic effect to be influenced by any one of the solution variables, including $\mathrm{pH}$, degree of relative supersaturation $(\sigma)$, ionic strength $(I), \mathrm{Ca}^{2+}$ to $\mathrm{CO}_{3}^{2-}$ ionic activity ratio $(R)$, and superficial velocity $(v)$, was investigated while keeping the other variables constant. The growth rate was suppressed completely in the presence of the magnetic field under low $\mathrm{pH}$ and supersaturation conditions. By contrast, the growth rate seemed to increase at high $\mathrm{pH}$ and relative supersaturation. A more surprising result is that the magnetic suppression effect on $\mathrm{CaCO}_{3}$ growth was observed except at unity activity ratio. The information gathered in this experiment might be used as a reference for understanding the performance of the anti-scale magnetic treatment device.
\end{abstract}

(c) 2008 Elsevier B.V. All rights reserved.

\section{Introduction}

Cooling water accounts for a large proportion of industrial process water, exchanging energy with the process material stream in a heat exchanger. After a long period of circulation in a cooling system, some of the water will evaporate, increasing the $\mathrm{Ca}^{2+}$ concentration. This causes sparingly soluble salts $\left(\mathrm{CaCO}_{3}\right.$ in majority) precipitate on the wall of pipes or exchangers to form scale, due to the solubility change caused by temperature and acidity variations $[1,2]$. To lower the $\mathrm{Ca}^{2+}$ concentration, generally a portion of the process water is discharged and replaced by fresh water. Hence, the use of an efficacious water-saving measure will help solve the water shortage problem.

A number of scale prevention techniques have been adopted. Acid treatment, often called pH control, is a common technique in large plants. An adequate amount of acid is added to the makeup water to lower its $\mathrm{pH}$, and most of the dissolved $\mathrm{CO}_{3}^{2-}$ and $\mathrm{HCO}_{3}^{-}$ ions are then transformed to gaseous $\mathrm{CO}_{2}$ and removed. The chief defect of this approach is that corrosion problem may result if too much acid is added [1]. Addition of certain chemical agents (usually polyelectrolytes or copolymers) of low concentration to process water is another scale-control technique [3,4]. This

\footnotetext{
* Corresponding author. Tel.: +8862 23620832; fax: +886223623040

E-mail address: cytai@ntu.edu.tw (C.Y. Tai).
}

technique has been widely practiced in recent years because of low cost and low rate of piping corrosion. The main disadvantage is the thermal instability of added chemicals and the contamination problem from discharge. Ion exchange technology has also been reported as successful for scale prevention [1], but is not popular due to its high installation cost and regular regeneration requirement. In addition to chemical scale prevention techniques, physical methods have also been adopted. Mechanical cleaning is often carried out when pipes become plugged by scale, which is an expensive and time-consuming method. Electromagnetic and ultrasonic waves have also been used for scale removal, but the results have not been satisfactory $[5,6]$.

Magnetic water treatment for scale prevention has been around for more than a century [1,7-9], and has been reported as being effective in many instances [10-12]. For example, Tye reported that magnetic treatment showed remarkable scaleprevention performance in systems with heated surfaces, such as heat exchangers [10]. Donaldson and Grimes monitored studies on the magnetic treatment in a wide range of systems, and pointed out that the magnetic treatment lessened the scale buildup significantly [11]. Another example has been reported by Kobe et al. [12] that a magnetic device was constructed and installed in a pilot plant. They found that it reduced the weight gains of the pipeline due to scale deposition.

To explore the magnetic effect on scale prevention, several mechanisms have been proposed. Researchers have reported that 


\begin{tabular}{|c|c|c|c|}
\hline \multicolumn{2}{|c|}{ Notation } & $M$ & molecular weight of $\mathrm{CaCO}_{3}(\mathrm{~g} / \mathrm{mol})$ \\
\hline$A$ & surface area of crystal $\left(\mathrm{m}^{2}\right)$ & $T$ & time $(s)$ \\
\hline$a_{i}$ & activity of the $i$ species $(\mathrm{mol} / \mathrm{L})$ & $V$ & superficial velocity \\
\hline$C_{i},(i)$ & concentration of the $i$ species $(\mathrm{mol} / \mathrm{L})$ & $V_{\mathrm{a}}$ & the volume of the added solution $(\mathrm{mL})$ \\
\hline$R_{\mathrm{g}}$ & crystal growth rate $\left(\mathrm{kg} / \mathrm{m}^{2}-\mathrm{s}\right)$ & $W$ & total mass of crystal $(\mathrm{g})$ \\
\hline G & linear crystal growth rate $(\mathrm{m} / \mathrm{s})$ & $z_{i}$ & valence of the $i$ species $(-)$ \\
\hline$I$ & ionic strength $(\mathrm{mol} / \mathrm{L})$ & $\sigma$ & relative supersaturation $(-)$ \\
\hline$K_{\text {ip }}$ & activity ionic product of $\mathrm{CaCO}_{3}\left(\mathrm{~mol}^{2} / \mathrm{L}^{2}\right)$ & {$\left[\mathrm{Ca}^{2+}\right]_{\mathrm{a}}$} & $\mathrm{Ca}^{2+}$ concentration of the titrated solution $(\mathrm{mol} / \mathrm{L})$ \\
\hline$K_{\mathrm{sp}}$ & activity solubility product of $\mathrm{CaCO}_{3}\left(\mathrm{~mol}^{2} / \mathrm{L}^{2}\right)$ & {$\left[\mathrm{Ca}^{2+}\right]_{\mathrm{o}}$} & $\mathrm{Ca}^{2+}$ concentration of the original solution $(\mathrm{mol} / \mathrm{L})$ \\
\hline$L$ & characteristic length of crystal $(\mu \mathrm{m})$ & & \\
\hline
\end{tabular}

the number of nucleated crystallites increased in the presence of a magnetic field. The rise in the nucleation rate resulted in less scaling because more small particles were suspended in the water instead of sticking onto the pipe wall $[2,13,14]$. Kirgintsev inferred that the observed magnetic effects on crystallization resulted from a decrease in interactions, which was magnetically induced, between water molecules, producing a high local concentration of $\mathrm{Ca}^{2+}$ and increasing the nucleation rate of $\mathrm{CaCO}_{3}$ [14]. Tebenikhin and Gusev attributed the increasing nucleation to the high probability of collision between cations and anions induced by the magnetic field $[15,16]$. Ellingsen and Vik supposed that the magnetic effects came from the change in surface charge/ electrokinetic parameters of charged solid particles due to the magnetic field [17]. Similar reasoning was also proposed by Raisen [18]. Crolet and Ledion conjectured that positively charged colloids formed in the supersaturated water under the influence of the magnetic field, thus accelerating the $\mathrm{CaCO}_{3}$ nucleation but suppressing the crystal growth [19]. Busch et al. [20] and Busch and Busch [21] observed that "magnetohydrodynamic effects", which are promoted by the flow of conducting fluid through the magnetic field, enhanced the corrosion of the metal housing and produced a precipitation initiator that favored the precipitation of scaling salts. On the other hand, Higashitani et al. found that the magnetic field could both reduce $\mathrm{CaCO}_{3}$ nucleation rate and increase the induction period. Reduction and delay in nucleation decreased the total amount of solid $\mathrm{CaCO}_{3}$ in the water also conceivable for scale prevention [22].

However, not all researchers have reported positive effects from magnetic fields. Hasson and Bramson did not observe an anti-scale effect of a magnetic field during scaling experiments with hard water [23]. Söhnel and Mullin judged from the crystallization theories and concluded that the existence of an effect of magnetic fields on crystal growth and nucleation of sparingly soluble salts is doubtful [24]. Moreover, some researchers indicated that the anti-scale effects were due to a side effect of the magnetic field, such as impurity dissolution [25] or pH change [26], not directly from the magnetic field. Baker and Judd [2] comprehensively grouped the above-mentioned mechanisms into four basic categories: (a) intramolecular/intraionic interaction [14], (b) Lorentz force effects [20,21], (c) dissolution of contaminants [25], and (d) interfacial effects (e.g., distortion of the double layer) [17-19,22]. The most plausible among them is the last, in which the interaction of the magnetic field with the charged species present on the interface affects crystal nucleation and growth, and generally draws the most attention.

Although the magnetic effects on $\mathrm{CaCO}_{3}$ crystal growth have been widely studied, conflicting results were reported. This was because the operating variables were not controlled, and may change during an experimental run as most of the studies used the free-drift technique. Such a change might occur, for example, when a decrease in solution $\mathrm{pH}$ during an experiment led to a decrease in supersaturation [27]. Further, the effects of solution conditions on $\mathrm{CaCO}_{3}$ growth or nucleation were easily confused with the effects of magnetic field [28]. In this study, the constantcomposition method, originally designed by Tomson and Nancollas and has been successfully used to study the crystallization of many calcium salts [29], was first applied to investigate the magnetic effects on crystal growth, with the solution conditions being kept constant during an experiment by means of autotitrators. Also, the experimental time was shortened from months $[28,29]$ to hours by evaluating the crystal growth rate from the titrated solution. Crystallization experiments of $\mathrm{CaCl}_{2} / \mathrm{Na}_{2} \mathrm{CO}_{3}$ reacting system were performed using natural calcite seeds suspended in a fluidized bed crystallizer. The crystal growth rates were measured in the presence or absence of magnetic field under various operating variables, including I (ionic strength), $\mathrm{pH}, \sigma$ (degree of relative supersaturation), and $\mathrm{R}\left(\mathrm{Ca}^{2+} / \mathrm{CO}_{3}^{2-}\right.$ activity ratio). The relations between these variables and the magnetic effects on calcite growth rate were discussed in this study.

\section{Experimental procedure}

\subsection{Crystallization system and the magnetic treatment device}

The experimental apparatus is similar to that reported elsewhere [30,31]. The main difference is that a magnetic treatment device, Descal-A-Matic DC-3, is incorporated into the system, as shown in Fig. 1. The crystallization system, including a fluidizedbed crystallizer, a storage tank, and a constant-composition control system, was used to measure the growth rate of $\mathrm{CaCO}_{3}$ crystal under different operating conditions. A detailed construction of the Descal-A-Matic DC-3 is given in Fig. 2. It consists of three pairs of permanent magnets arrayed in line and fixed in a steel tube. A magnetic field with a flux density of 1800 Gauss is induced in the gap between the permanent magnets and the steel tube. In operation, a supersaturated solution is magnetized when passing through the gap of the magnetic device. The magnetic device applies a magnetic field that is oriented approximately orthogonal to the direction of flow, and is regarded as a Class III magnetic field according to Gruber and Carda's classification [32].

\subsection{Preparation of the supersaturated solution}

The $\mathrm{CaCO}_{3}$ supersaturated solution of specified conditions was prepared by mixing the standardized 0.1-M solutions of $\mathrm{CaCl}_{2}$ and $\mathrm{Na}_{2} \mathrm{CO}_{3}$, and its $\mathrm{pH}$ was adjusted by adding $\mathrm{HCl}$ or $\mathrm{NaOH}$ solution. All the solutions were prepared from the deionized water with a resistivity of $18.2 \mathrm{M} \Omega \mathrm{cm}$, supplied by the PURELAB Maxima ELGA system. The operating variables, $I$ (ionic strength), $R\left(\mathrm{Ca}^{2+}\right.$ to $\mathrm{CO}_{3}^{2-}$ activity ratio), and $\sigma$ (relative supersaturation), were calculated by 


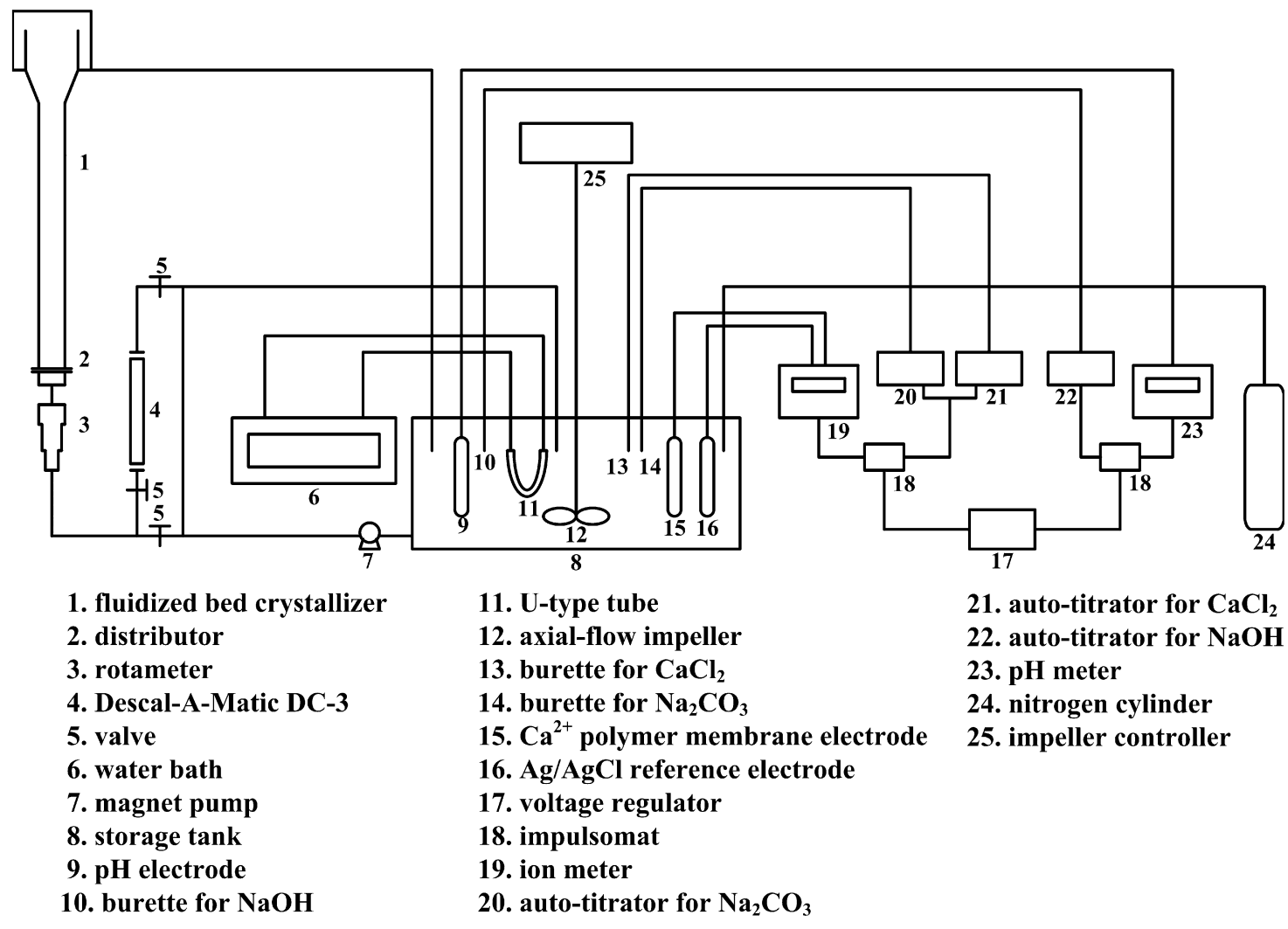

Fig. 1. Diagram of constant composition crystallization system incorporating a magnetic treatment device.

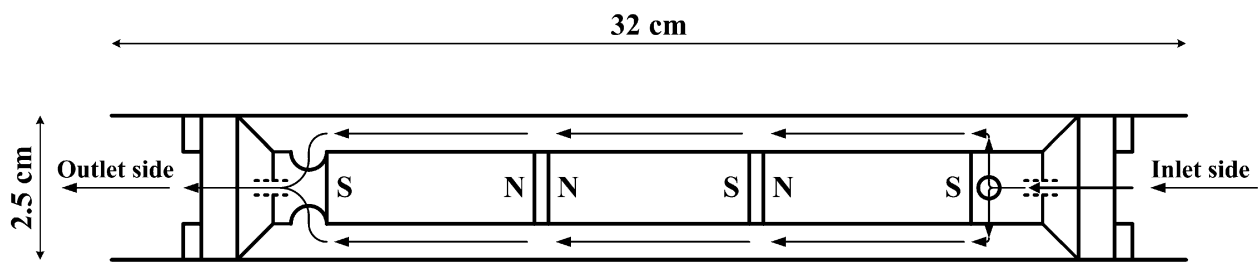

Fig. 2. Detailed structure of the Descal-A-Matic DC-3 magnetic device.

the following equations [33]:

$$
\begin{aligned}
I= & \frac{1}{2} \sum_{i} C_{i} z_{i}^{2}=\frac{1}{2}\left(2^{2}\left[\mathrm{Ca}^{2+}\right]+2^{2}\left[\mathrm{CO}_{3}^{2-}\right]+\left[\mathrm{CaOH}^{+}\right]+\left[\mathrm{CaHCO}_{3}^{+}\right]+\left[\mathrm{HCO}_{3}^{-}\right]\right. \\
& \left.+\left[\mathrm{Na}^{+}\right]+\left[\mathrm{Cl}^{-}\right]+\left[\mathrm{H}^{+}\right]+\left[\mathrm{OH}^{-}\right]\right) \\
= & 2\left[\mathrm{Ca}^{2+}\right]+2\left[\mathrm{CO}_{3}^{2-}\right]+\frac{1}{2}\left[\mathrm{CaOH}^{+}\right]+\frac{1}{2}\left[\mathrm{CaHCO}_{3}^{+}\right]+\frac{1}{2}\left[\mathrm{HCO}_{3}^{-}\right]+\frac{1}{2}\left[\mathrm{Na}^{+}\right] \\
& +\frac{1}{2}\left[\mathrm{Cl}^{-}\right]+\frac{1}{2}\left[\mathrm{H}^{+}\right]+\frac{1}{2}\left[\mathrm{OH}^{-}\right]
\end{aligned}
$$

$R=\frac{a_{\mathrm{Ca}^{2+}}}{a_{\mathrm{CO}_{3}^{2-}}}$

$\sigma=\sqrt{\frac{K_{\mathrm{ip}}}{K_{\mathrm{sp}}}}-1$

where $K_{\mathrm{ip}}$ is the activity ionic product and $K_{\mathrm{sp}}$ is the activity solubility product. The amount of substances needed was calculated by a computer program used by Tai et al. [33], and was measured by an auto-titrator with a precision of $0.001 \mathrm{~mL}$. For example, to prepare a supersaturated solution of $6 \mathrm{~L}$ at conditions of $\mathrm{pH}=9.0, \quad I=0.018 \mathrm{M}, \quad \sigma=1.0, R=5.54$, and $T=25^{\circ} \mathrm{C}$, a standardized solution of 36.13 and $95.60 \mathrm{~mL}$ for $\mathrm{CaCl}_{2}$ and $\mathrm{Na}_{2} \mathrm{CO}_{3}$ were required, respectively. To prevent undesired nucleation, a mixing procedure was carefully followed. First, 95.60- $\mathrm{mL} \mathrm{Na}_{2} \mathrm{CO}_{3}$ solution was poured into 4 -L deionized water already in the stirred storage tank, and solution $\mathrm{pH}$ was adjusted to 9.30, which was slightly higher than the set value, by adding $\mathrm{HCl}$ solution. Then, $1 \mathrm{~L}$ of $\mathrm{CaCl}_{2}$ solution diluted from $36.13-\mathrm{mL}$ standardized solution was poured slowly into the storage tank. Finally, the solution $\mathrm{pH}$ was accurately adjusted to $9.00 \pm 0.01$, while the solution volume was made up to $6 \mathrm{~L}$ with deionized water. The $6-\mathrm{L}$ supersaturated solution was then ready for experiment and its final concentration of $\mathrm{Ca}^{2+}$ and $\mathrm{CO}_{3}^{2-}$ ion was $5.625 \times 10^{-4}$ and $1.015 \times 10^{-4} \mathrm{M}$, respectively. For other solution conditions, the required amount of reactants and concentration of each species were different, but the general procedures were the same.

\subsection{Experimental procedures for crystal growth}

In the growth experiment a typical set of solution conditions was as follows: $\mathrm{pH}=9.0, \quad I=0.018 \mathrm{M}, \quad \sigma=1.0, \quad R=5.54$, $v=0.0473 \mathrm{~m} / \mathrm{s}$. The interaction between any one of the solution properties with the magnetic field could be investigated while keeping the other variables constant. Referring to Fig. 1, with or without passing the Descal-A-Matic (4), the supersaturated solution was pumped by a magnet pump (7) from the storage 
tank (8) through a rotameter (3) and then into the fluidized bed (1), which was a PVC column with a distributor (2) at the bottom to give an even flow. The calcite seed crystals grew inside the PVC column. After that the solution overflowed back to the storage tank. Calcite seeds of an average size of $774 \mu \mathrm{m}$ and a total weight of $25 \mathrm{~g}$ were introduced into the fluidized bed to begin an experimental run when the temperature, $\mathrm{pH}$, and $\mathrm{Ca}^{2+}$ electric potential signals became steady. The seeds were wetted with the solution prior to charging into the fluidized bed to prevent the seeds from being carried away by the circulating solution. The crystal growth process may cause a decrease in solution concentration and, sometimes, a slight $\mathrm{pH}$ disturbance, and the constant-composition system came to work by adding the reactants and $\mathrm{NaOH}$ solution into the storage tank instantaneously. The use of $\mathrm{pH}$ electrode (9) here was for the control of $\mathrm{pH}$ only, not for constant composition. The constant-composition system consisted of a pH meter (23), an ion meter (19), an impulsomat (18), and auto-titrators (20-22). The solution $\mathrm{pH}$ and $\mathrm{Ca}^{2+}$ electric potential were detected at an interval of $7.5 \mathrm{~s}$. If the $\mathrm{pH}$ meter or ion meter received the signal showing a drop in $\mathrm{pH}$ or $\mathrm{Ca}^{2+}$ electric potential from $\mathrm{pH}$ electrode (9) or $\mathrm{Ca}^{2+}$ electrode (15), the impulsomat (18) would transmit an order to the auto-titrators to replenish the two reactants of the same concentration simultaneously (due to the equimolar consumption of reactants during $\mathrm{CaCO}_{3}$ formation) or the $\mathrm{NaOH}$ solution into the system instantaneously, and maintain the $\mathrm{pH}$ and $\mathrm{Ca}^{2+}$ concentration at the set value.

The titration curve, which showed the amount of make-up solution added to the system, was recorded automatically. It was then used to evaluate the linear crystal growth rate of the $\mathrm{CaCO}_{3}$. The total solution volume and concentrations of starting solution and titrant chosen by Tomson and Nancollas [29] were $150 \mathrm{~mL}$, $8 \times 10^{-4}$, and $0.01 \mathrm{M}$, respectively. In this research, the concentration of starting solution was lower $\left(5.625 \times 10^{-4} \mathrm{M}\right.$ as stated in Section 2.2), and the total solution was much larger, $6 \mathrm{~L}$ versus $150 \mathrm{~mL}$, making it easier to maintain the constant composition environment. The concentrations of titrants, $\mathrm{CaCl}_{2}$ and $\mathrm{Na}_{2} \mathrm{CO}_{3}$ solutions, were chosen as $0.1 \mathrm{M}$, following that reported by Tai et al. [30]. A more concentrated titrant may induce undesired primary nucleation, while a diluted one might need a titrant volume that is larger than that of the auto-titrator's storage bottle. Although the concentration of titrant and starting solution were not the same as that reported by Tomson and Nancollas [29], a real constant-composition situation was able to achieve as checked by inductively coupled plasma spectrometer (ICP, Optima-3000XL). During an experimental run, the $\mathrm{Na}^{+}$and $\mathrm{Cl}^{-}$ ions would accumulate, increasing the ionic strength of the solution. However, the change in growth rate was negligible due to an increment of ionic strength within $5 \%$. After an experimental run, the seed crystals were removed, washed, and then kept in a supersaturated solution for the next experiment. A voltage regulator (17) was installed to the experimental system in order to reduce noise caused by unstable power supply and stabilize the operation of constant-composition system. Nitrogen gas (24) was provided as blanket to prevent the absorption of $\mathrm{CO}_{2}$ from air, as the absorbed $\mathrm{CO}_{2}$ would distort the growth rate.

\subsection{Determination of crystal growth rate}

Starting from the crystal growth rate in terms of weight flux, $R_{\mathrm{g}}$

$R_{\mathrm{g}}=\frac{1}{A} \frac{\mathrm{d} W}{\mathrm{~d} t}$

the linear crystal growth rate, $G$, was derived by Tai et al. [33] as
$G=\frac{L M}{3 W}\left(\left[\mathrm{Ca}^{2+}\right]_{\mathrm{a}}-\left[\mathrm{Ca}^{2+}\right]_{\mathrm{o}}\right) \frac{\mathrm{d} V_{\mathrm{a}}}{\mathrm{d} t}$

where $A$ is the surface area of a crystal seed, $L$ the characteristic length of crystal seeds $(774 \mu \mathrm{m}), W$ the total mass of crystal seeds, $R_{\mathrm{g}}$ the weight flux, $M$ the molecular weight of $\mathrm{CaCO}_{3}, V_{\mathrm{a}}$ the volume of titrated solution, $t$ the experimental time, and $\left[\mathrm{Ca}^{2+}\right]_{\mathrm{o}}$ and $\left[\mathrm{Ca}^{2+}\right]_{\mathrm{a}}$ for the $\mathrm{Ca}^{2+}$ concentration of the original solution and added solution, respectively.

The titration volume of a typical run at $\mathrm{pH}=9.0, I=0.018 \mathrm{M}$, $\sigma=1.0$, and $R=5.54$ was recorded automatically as curve (a) shown in Fig. 3, and curve (b) was that of the same condition without adding crystal seeds. The arrow, which indicated the starting point of magnetization, cuts the figure into two sections. As shown in curve (b) of Fig. 3, almost no solution was added to the system either in Sections 1 or 2, meaning that the magnetization on the supersaturated solution did not disturb the response of the electrodes. As for curve (a), the titration curve was nearly a straight line before magnetization in Section 1, and Section 2 was a curved line at the beginning, then changed gradually to a straight line after the growth rate became steady, approximately at a run time of $6000 \mathrm{~s}$ for the specific run. The slopes of the two fitted straight lines were used to calculate the crystal growth rate according to Eq. (5) for the growth rates without and with magnetization, respectively. The experiments of calcite growth were operated in the metastable region, where no nucleation occurred. If nucleation had occurred, the titration curve would have been jumped, instead of a smooth curve. To make sure that the composition was maintained constant after magnetization, the solution was sampled and the total calcium concentration was checked by an inductively coupled plasma spectrometer (ICP, Optima-3000XL) immediately after every experimental run. Because the $\mathrm{Ca}^{2+}$ concentration is a function of $\mathrm{pH}$, the percentage of $\mathrm{Ca}^{2+}$ remains the same under constant $\mathrm{pH}$ and total calcium concentration. Therefore, the check of total calcium using ICP assured a constant $\mathrm{Ca}^{2+}$ and thus constant $\mathrm{CO}_{3}^{2-}$ concentration due to stoichiometric feeding. Further, the concentration of iron ions, which would reduce the calcite growth rate [25], was also checked occasionally to make sure no iron dissolved from the magnetic water treatment device. The detection limit of ICP for Fe was $2.9 \mu \mathrm{g} / \mathrm{L}\left(2.9 \times 10^{-3} \mathrm{ppm}\right)$, and the Fe concentration of the solutions in this study was of the undetectable level.

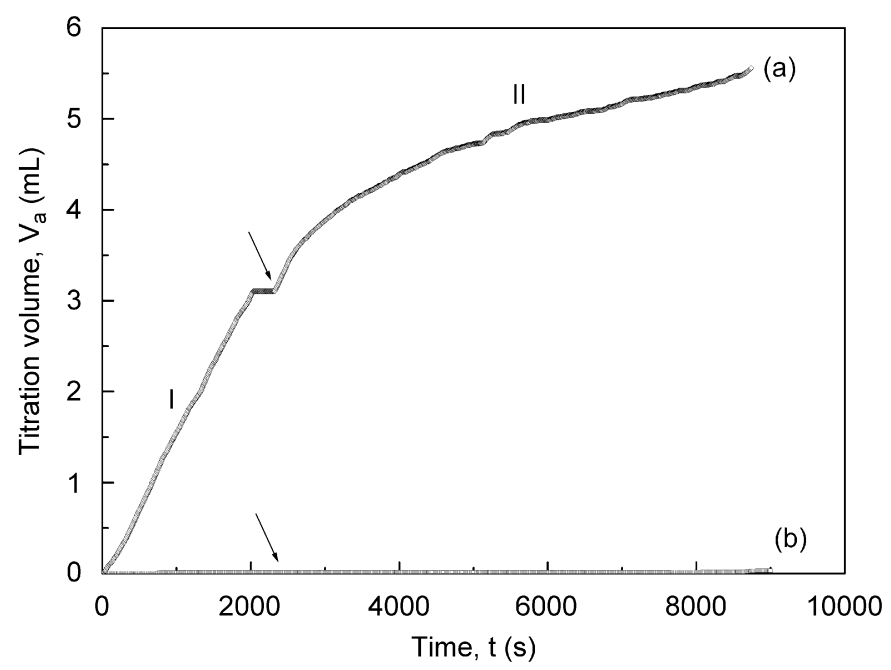

Fig. 3. A typical titration curve recorded under the following operating conditions: $\mathrm{pH}=9.0, \sigma=1.0, I=0.018 \mathrm{M}, R=5.54, T=25^{\circ} \mathrm{C}$. The arrow indicates the starting point of magnetization, and I and II sections are the titration curves without and with magnetization, respectively: (a) with seeding crystals and (b) without seeding crystals. 

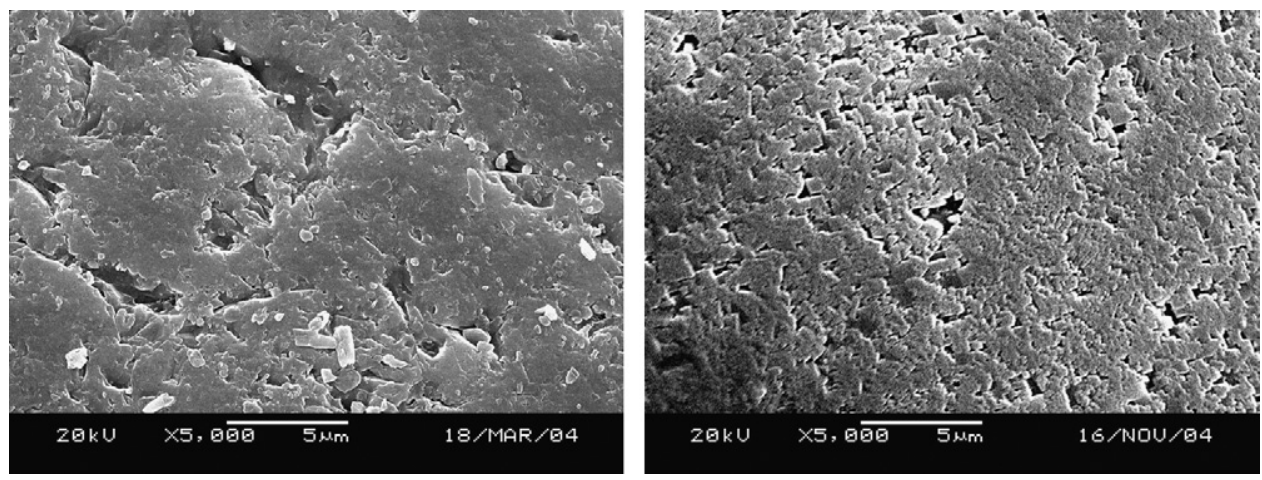

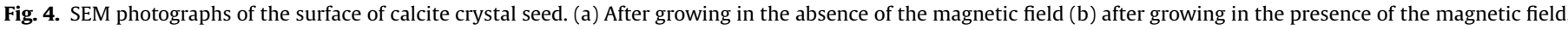

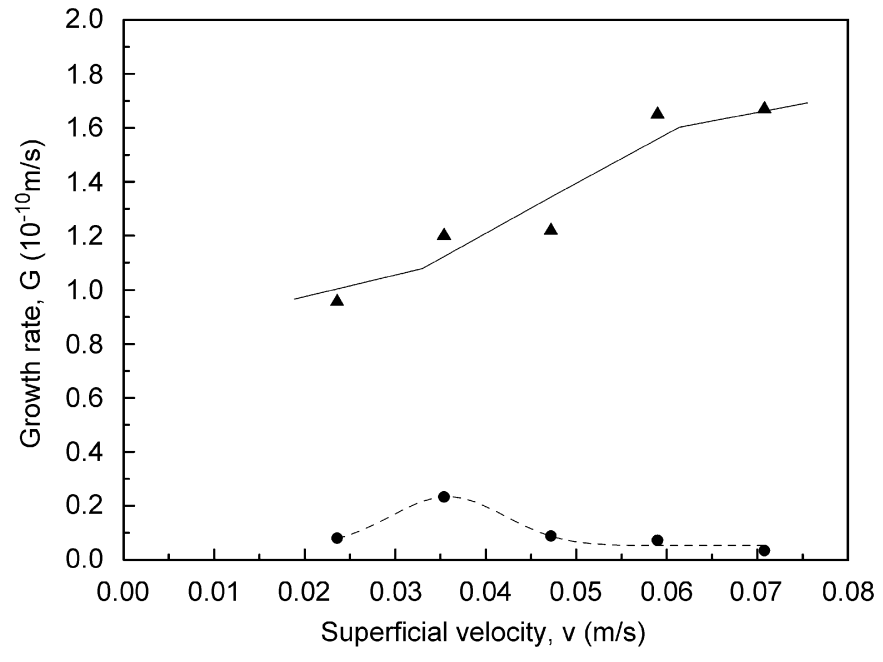

Fig. 5. Growth rates of calcite as a function of superficial velocity, with other variables kept constant. $\boldsymbol{\Delta}$ : Without magnetic treatment. $\bullet$ : With magnetic treatment of Descal-A-Matic DC-3.

The SEM photographs of the crystal surface of calcite seed are shown in Fig. 4, in which Figs. 4(a) and (b) are the seeds after growing in the absence and presence of the magnetic field, respectively. There is no obvious difference between them. It implied that there was no morphology change on the crystal surface of calcite seeds during the magnetization process.

\section{Results and discussion}

\subsection{Effects of magnetic field at various superficial velocities}

In this session, magnetic effects on the crystal growth of calcite at different superficial velocities were investigated. The superficial velocity was the primary factor affecting the mass-transfer resistance of crystal growth [33]. In this experiment, the superficial velocity was varied form 0.0236 to $0.0708 \mathrm{~m} / \mathrm{s}$, but other parameters kept at the typical setting conditions, i.e., $\mathrm{pH}=9.0$, $I=0.018 \mathrm{M}, \sigma=1.0, R=5.54$, and $T=25^{\circ} \mathrm{C}$. The growth rate data as a function of the superficial velocity are plotted in Fig. 5. The calcite growth rate without magnetization slightly increased as the superficial velocity increased. This was attributed to the decrease in mass transfer resistance at higher velocities [30]. When the superficial velocity exceeded $0.0590 \mathrm{~m} / \mathrm{s}$, the calcite growth rate tended to level off, meaning that the mass transfer resistance was no longer significant. Under the influence of Descal-A-Matic DC-3, the calcite growth rate decreased on the

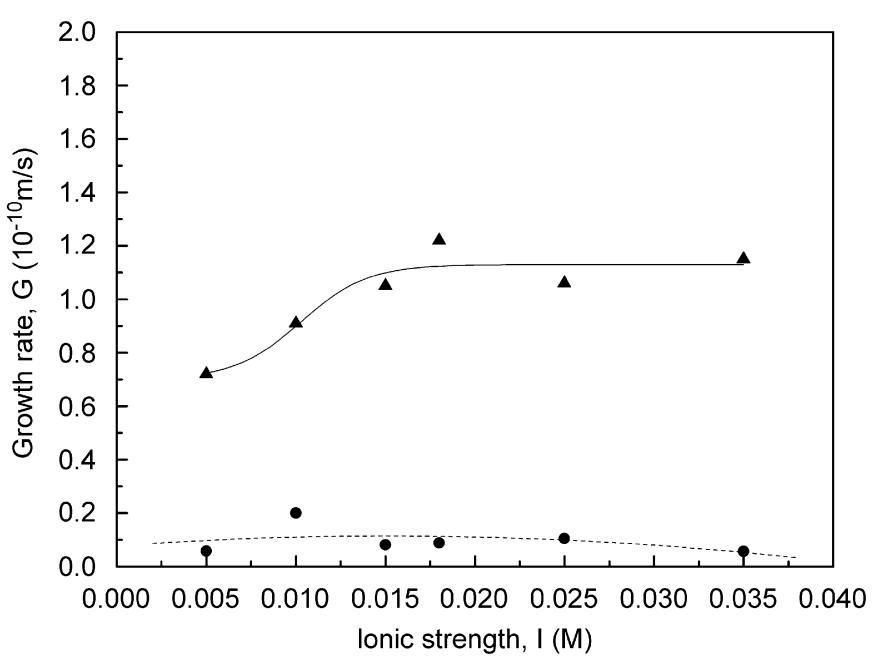

Fig. 6. Growth rates of calcite as a function of ionic strength, with other variables kept constant. $\boldsymbol{\Delta}$ : Without magnetic treatment. $\bullet$ : With magnetic treatment of Descal-A-Matic DC-3.

order of $10^{-11} \mathrm{~m} / \mathrm{s}$, a reduction by more than an order of magnitude compared with that in the absence of magnetic field. Since the growth rate data were very low in the presence of magnetic field, the data at superficial velocity of $0.035 \mathrm{~m} / \mathrm{s}$ did not show a maximum. Instead, the data were scattered.

\subsection{Effects of the magnetic field at various levels of ionic strength}

Ionic strength, which determines the electrical double layer thickness, may also influence the mass-transfer resistance of crystal growth in a manner similar to that of the superficial velocity [31]. This series of experiments was carried out under differing ionic strengths ranging from 0.005 to $0.035 \mathrm{M}$, with other parameters fixed. Fig. 6 shows the effect of ionic strength on the calcite growth rate with/without magnetization. The calcite growth rate without magnetization increased with increasing ionic strength in the lower region, but remained constant after the ionic strength exceeded $0.018 \mathrm{M}$. The phenomena agreed with the results of Tai et al. [30,31] and could be explained as the compression of the electric double layer at higher ionic strengths [34]. When ionic strength exceeded $0.018 \mathrm{M}$, the electrical double layer thickness was almost compressed to an almost constant thickness, which gave a constant mass-transfer resistance. When the supersaturated solution passed through the Descal-A-Matic DC-3, calcite growth rate was reduced on the order of $10^{-11} \mathrm{~m} / \mathrm{s}$. Whatever the ionic strength was, the magnetic field suppressed 


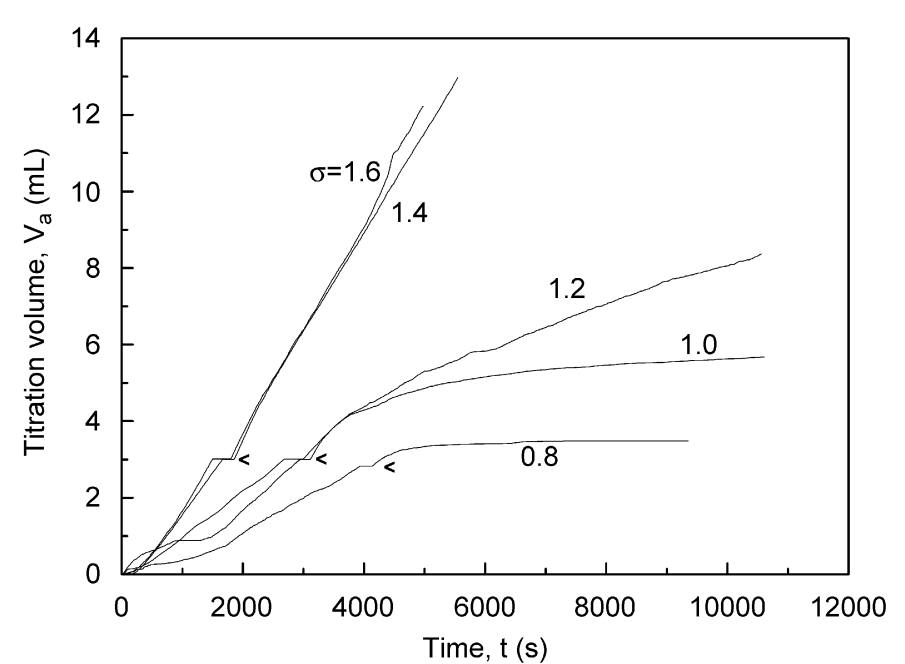

Fig. 7. Titration curves of $\mathrm{CaCl}_{2}$ standardized solution recorded at different levels of relative supersaturation, with other variables kept constant. The symbol "<" indicates the starting point of magnetization.

the calcite growth rate by more than $80 \%$. The suppression of growth rate was dominated by the magnetic field and was not influenced by the ionic strength in the range studied.

\subsection{Effects of magnetic field at various levels of supersaturation}

Supersaturation is the driving force for crystal growth. To investigate the magnetic effects at various levels of relative supersaturation, all the operating variables were fixed but the relative supersaturation, which was varied from 0.8 to 1.6. Fig. 7 gives the titration curves recorded by the auto-titrator, in which the curves representing a higher degree of relative supersaturation had a greater slope with or without magnetization. After magnetization, the slopes of the curves decreased gradually at lower levels of relative supersaturation, but increased at higher levels, which meant that the magnetic effect did not appear immediately but needed some time to develop. This also explained why magnetic effects could be observed in most of the recirculatory systems, but disappeared in most of the singlepass trials, in industrial application of the magnetic devices [2]. In this experiment, as the relative supersaturation increased from 0.8 to 1.6 , the growth rate of calcite without magnetization increased from $0.916 \times 10^{-10}$ to $2.790 \times 10^{-10} \mathrm{~m} / \mathrm{s}$, as shown in Fig. 8 . This result shows good agreement with that reported by Tai et al. [30,31] at similar growth conditions. At lower degrees of relative supersaturation, less than 1.2 , the magnetic device showed a marked retardation effect, and almost completely stopped the calcite growth at $\sigma=0.8$. On the other hand, the growth rate enhanced after magnetization when the relative supersaturation was higher than 1.4. It is possible that the magnetic field was less effective for retarding calcite growth at higher relative supersaturation because the high level of relative supersaturation strongly favored the formation of calcite [27]. One possible interpretation of these results is that increase of the growth rate was due to nucleation at high relative supersaturation. However, this was not possible because the magnetic field increased the induction time, which will be reported later in this communication. Different effects of magnetic field at different levels of relative supersaturation have been reported in the literature. Dalas and Koutsoukos measured the growth rate of calcite seeds in a constant $\mathrm{pH}$ environment using a stirred tank. They found that the growth rate decreased under the influence of magnetic field, and the suppression percentage generally in-

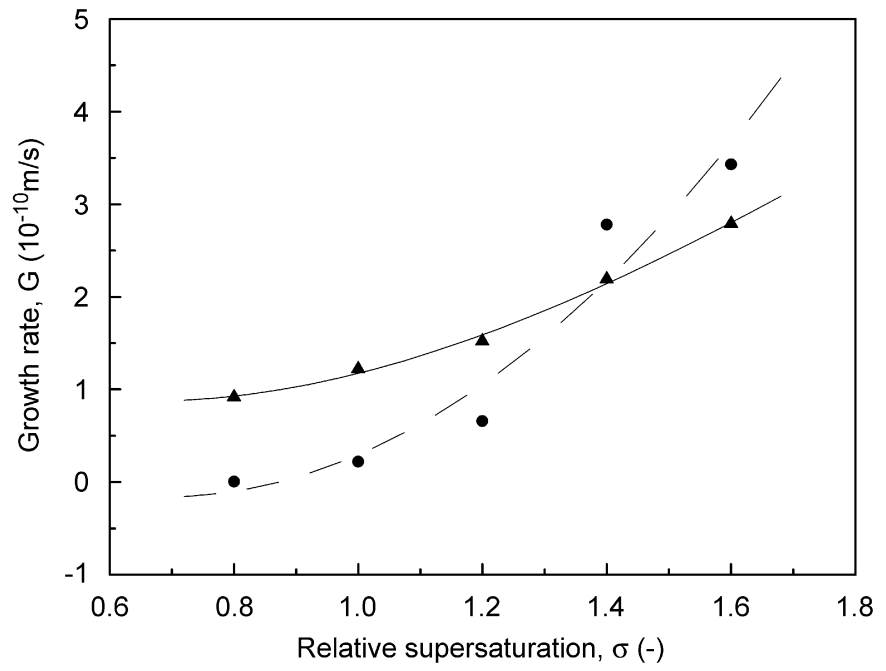

Fig. 8. Growth rates of calcite as a function of relative supersaturation, with other variables kept constant. $\boldsymbol{\Delta}$ : Without magnetic treatment. $\bullet$ : With magnetic treatment of Descal-A-Matic DC-3.

creased with decreasing supersaturation [35]. However, Hasson and Bramson recorded no change in either the growth rate of scale deposition or the deposit tenacity after test durations from 15 to $35 \mathrm{~h}$, and concluded that magnetic field was ineffective in scale prevention at very high levels of relative supersaturation, higher than 20 [23]. Although the results reported by Dalas and Koutsoukos [35] and Hasson and Bramson [23] for low supersaturation and high supersaturation, respectively, were different, they were consistent with our results.

\subsection{Effects of magnetic field at various $p H$ values}

In this part of the experiment, the solution $\mathrm{pH}$ was varied from 8.5 to 10.5 , while the other conditions were kept constant. The titration curves are similar to that of Fig. 7 and are not shown here. The calcite growth rates for the cases with and without magnetization increased as the solution $\mathrm{pH}$ increased, as shown in Fig. 9. This trend is similar to that reported by Tai et al. $[30,31]$ for the case without magnetization. The two sets of data had a cross point at the $\mathrm{pH}$ around 10.0, below which the calcite growth rate was suppressed and above which the growth rate was enhanced. The enhancement was $34 \%$ at $\mathrm{pH}=10.5$. In the literature, Dalas and Koutsoukos [35], Gabrielli et al. [36], and Kobe et al. [12] also observed a suppression effect of magnetic field on the calcite growth under low pH condition; however, Parsons et al. [26] discovered that the $\mathrm{pH}$ played a different role in the growth process under the influence of the magnetic field. They demonstrated a scale reduction caused by magnetic treatment when the starting solution $\mathrm{pH}$ was 8.0 and without $\mathrm{pH}$ regulation. In their experiment, the solution $\mathrm{pH}$ dropped quickly to 7.5 then increased gradually. However, the effect of magnetic treatment on scale formation was eliminated under $\mathrm{pH}$ values regulated at 8.0 and 8.5. In our research, although the cross point of $\mathrm{pH}$ effect was not the same as that reported by Parsons et al. [26], a similar trend was also observed: $\mathrm{CaCO}_{3}$ crystal growth was inhibited at low $\mathrm{pH}$ but unaffected at higher $\mathrm{pH}$ under the influence of the magnetic field. Further, the different magnetic effects at different levels of $\mathrm{pH}$ only reported by Ellingsen and Kristiansen [37] were confirmed in this experiment, although the trend was not quite the same. The different trend may be caused by the different operational procedures; in fact, the composition of ground water they used was more complicated than that used in this study. 


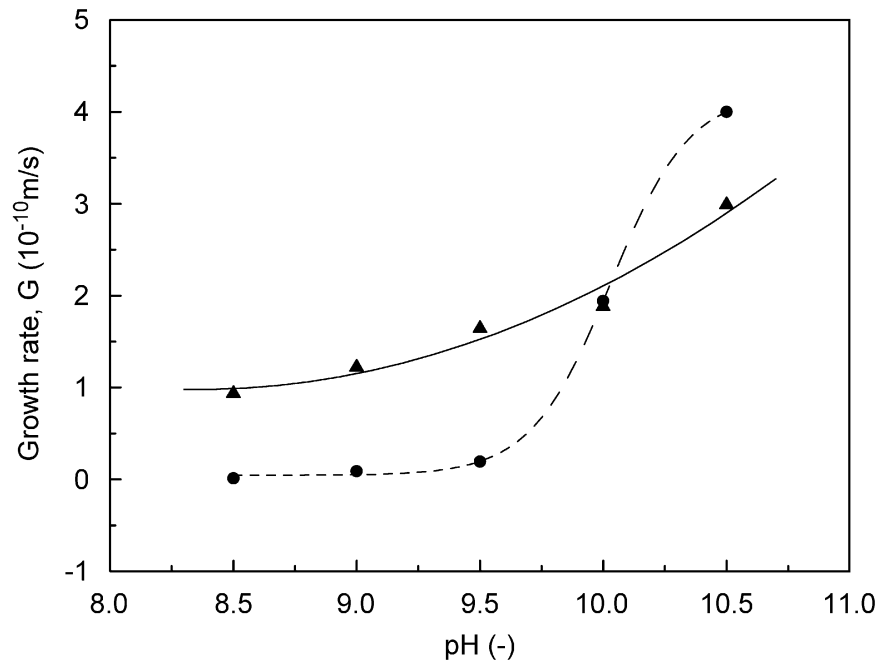

Fig. 9. Growth rates of calcite as a function of $\mathrm{pH}$, with other variables kept constant. $\mathbf{\Delta}$ : Without magnetic treatment. $\bullet$ : With magnetic treatment of DescalA-Matic DC-3.

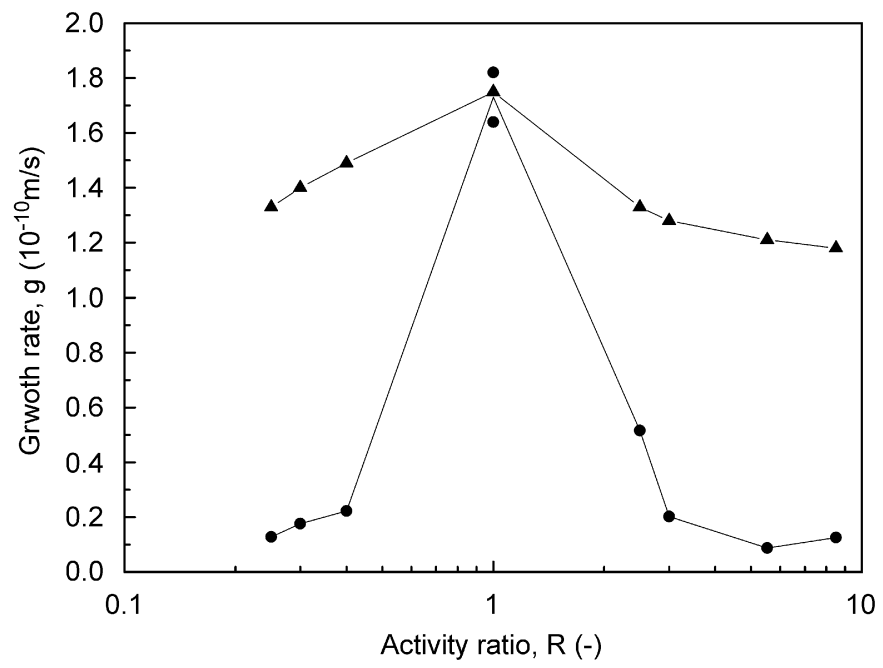

Fig. 10. Growth rates of calcite as a function of activity ratio, with other variables kept constant. $\boldsymbol{\Delta}$ : Without magnetic treatment. $\bullet$ : With magnetic treatment of Descal-A-Matic DC-3.

\subsection{Effects of magnetic field at various activity ratios}

For some sparingly soluble salts, such as $\mathrm{PbF}_{2}[38]$ and $\mathrm{CaCO}_{3}$ [31], the crystal growth rate may be influenced by the activity ratio of reactants. Experimental results with conditions at different activity ratios of $\mathrm{Ca}^{2+}$ to $\mathrm{CO}_{3}^{2-}$, from 0.25 to 8.5 , were reported in this section. As shown in Fig. 10, the calcite growth rate reached a maximum without using the Descal-A-Matic DC-3 at the particular point, $R=1.0$, and decreased as the ratio was off from unity. At this particular point, there was no significant change in calcite growth rate using the Descal-A-Matic DC-3. The experiment at $R=1.0$ was repeated and a similar result was obtained. As the activity ratio was off from unity, the decay of growth rate after magnetization increased. The crystal growth rate was suppressed by more than $90 \%$ at higher or lower activity ratios. The influence of the activity ratio on the crystal growth rate has also been found in other chemical species. For example, Stubičar et al. studied a $\mathrm{PbF}_{2}$ crystallization system and observed that the effective order of crystallization apparently increased when the activity ratio shifted from more than 1 to less than 1 , which indicated a change in crystal growth kinetics [38].
One variable not studied in this experiment was the presence of impurities, which are usually contained in process water. Some metal ions, such as $\mathrm{Mg}^{2+}$ and $\mathrm{Fe}^{3+}$, will favor the formation of aragonite; while $\mathrm{Mn}^{2+}$ and $\mathrm{Pb}^{2+}$ ions will favor calcite $[39,40]$. Thus the magnetic effect might be influenced by the presence of impurities, which will make the problem more complicated. The magnetic effect influenced by the presence of impurities is under investigation in our laboratory.

\section{Conclusions}

A fluidized bed was used to study the magnetic effect on the growth of calcite crystals suspended in a constant-composition environment. The suppression effect of a magnetic field using the Descal-A-Matic DC-3 was confirmed in the solution of low pH and relative supersaturation, and unequaled $\mathrm{Ca}^{2+}$ and $\mathrm{CO}_{3}^{2-}$ activity. The growth of calcite was almost stopped at certain specific conditions. By contrast, the magnetic field not only failed to reduce the growth rate of calcite at high relative supersaturation, high $\mathrm{pH}$, and a unity activity ratio of $\mathrm{Ca}^{2+}$ to $\mathrm{CO}_{3}^{2-}$, but increases in the calcite growth at $\mathrm{pH}>10$ and $\sigma>1.4$ were observed. The ionic strength and superficial velocity of solution did not influence the magnetic effect, i.e., in the studied range of both variables magnetic field suppressed the calcite growth. The results obtained from the growth experiment in this study can be used to reconcile some of the conflicting results reported in the literature. Suppose the effect of magnetic device on anti-scaling does exist, the experimental results obtained in this research imply that magnetic devices might work well only at low levels of $\mathrm{pH}$ and relative supersaturation with the process water recirculating within the magnetized system.

\section{Acknowledgment}

The authors gratefully acknowledge financial support provided by the National Science Council of the Republic of China (Taiwan).

\section{References}

[1] J. Glater, J.L. York, K.S. Campbell, Scale Formation and Prevention, in: K.S. Spiegler, A.D.K. Laird (Eds.), Principles of Desalination, Academic Press, New York, 1980, pp. 627-678.

[2] J.S. Baker, J.D. Judd, Water Res. 30 (1996) 247.

[3] M.M. Reddy, G.H. Nancollas, Desalination 12 (1973) 61.

[4] P. Shakkthivel, R. Sathiyamoorthi, T. Vasudevan, Desalination 164 (2004) 111.

[5] B.D. Sinezhuk, T.Y. Fedoruk, S.V. Mal'ko, Sov. J. Water Chem. Technol. 9 (1987) 29.

[6] X.K. Xing, C.F. Ma, Y.C. Chen, Chem. Eng. Technol. 28 (2005) 1540.

[7] A.T. Hay, Improvement in electrical protection for boilers. US Patent No. 140196, June 24, 1873.

[8] A. Faunce, S. Cabell, Electric means for preventing boiler incrustation. US Patent No. 438579, October 14, 1890.

[9] Y. Wang, A.J. Babchin, L.T. Chernyi, R.S. Chow, R.P. Sawatzky, Wat. Res. 31 (1997) 346.

[10] A. Tye, Resource 1 (1993) 25.

[11] D. Donaldson, S. Grimes, New Sci. 18 (1988) 43.

[12] S. Kobe, G. Dražić, P.J. McGuiness, J. Stražišar, J. Magn. Magn. Mater 236 (2001) 71.

[13] R. Gehr, Z.A. Zhai, J.A. Finch, S.R. Rao, Water Res. 29 (1995) 933.

[14] A.N. Kirgintsev, Russ. J. Phys. Chem. 45 (1971) 477.

[15] E.F. Tebenikhin, B.T. Gusev, Electrical Power Stations, vol. 8, Energy Press, Moscow, Russia, 1968, pp. 49-52.

[16] E.F. Tebenikhin, B.T. Gusev, Elek. Sta., Cited in Chemical Abstracts 70 (1969) $15385 y$.

[17] F.T. Ellingsen, E.A. Vik, A revue of scale formation with emphasis on magnetic water treatment. In: Proceedings of 14th World Congress of International Water Supply Association, Zurich, Switzerland, 1982, SS8, p. 12.

[18] E. Raisen, The control of scale and corrosion in water systems using magnetic fields. Corrosion 84 National Association of Corrosion Engineers, New Orleans U.S, Paper No. 117, 1984.

[19] J.L. Crolet, J. Ledion, Tech. Sci. Meth. L'Eau. 83 (1988) 435 
[20] K.W. Busch, M.A. Busch, D.H. Parker, R.E. Darling, J.L. McAtee Jr., NACE 42 (1986) 211.

[21] K.W. Busch, M.A. Busch, Desalination 109 (1997) 131

[22] K. Higashitani, A. Kage, S. Katamura, J. Colloid Interf. Sci. 156 (1993) 90.

[23] D. Hasson, D. Bramson, Ind. Eng. Chem. Process Des. Dev. 24 (1985) 588.

[24] O. Söhnel, J.W. Mullin, Chem. Ind. 11 (1988) 356.

[25] S. Takasaki, K.I. Parsiegla, J.L. Katz, J. Crystal Growth 143 (1994) 261.

[26] S.A. Parsons, B.L. Wang, S.J. Judd, T. Stephenson, Water Res. 31 (1997) 339

[27] C.Y. Tai, F.B. Chen, AIChE J. 44 (1998) 1790.

[28] E. Chibowski, L. Hołysz, A. Szcześ, Colloid Surf. A-Physicochem. Eng. Aspects 222 (2003) 41.

[29] M.B. Tomson, G.H. Nancollas, Science 200 (1978) 1059.

[30] C.Y. Tai, J.H. Lu, J.K. Wu, J. Chin. Inst. Chem. Eng. 36 (2005) 443.
[31] C.Y. Tai, M.C. Chang, C.K. Wu, Y.C. Lin, Chem. Eng. Sci. 61 (2006) 5346.

[32] C.E. Gruber, D.D. Carda, Performance analysis of permanent magnet type water treatment devices, WSA Research Report: Final Report, Water Quality Association, 1981.

[33] C.Y. Tai, W.C. Chien, C.Y. Chen, AIChE J. 45 (1999) 1605.

[34] R.J. Hunter, Introduction to Modern Colloid Science, Oxford University Press, 1993, pp. 210-215.

[35] E. Dalas, P.G. Koutsoukos, J. Crystal Growth 96 (1989) 802.

[36] C. Gabrielli, E. Jaouhari, G. Maurin, M. Keddam, Water Res. 35 (2001) 3249

[37] F.T. Ellingsen, H. Kristiansen, Vatten 4 (1979) 309.

[38] N. Stubičar, M. Ščrbak, M. Stubičar, J. Crystal Growth 100 (1990) 261.

[39] O. Söhnel, J.W. Mullin, J. Crystal Growth 60 (1982) 239.

[40] H. Roques, A. Girou, Water Res. 8 (1974) 907. 